\title{
BARGAINING AND THE TIMING OF INVESTMENT
}

\author{
Martin W. Cripps* \\ University of Warwick, \\ Coventry CV4 7AL, UK. \\ m.w.cripps@warwick.ac.uk \\ July 1994 \\ Revised July 1995
}

\begin{abstract}
The joint determination of the timing of investment and wage bargaining is modelled. Two cases are considered: (a) There is an alternating-offer bargaining game over binding wage contracts and production is possible only when agreement is reached. (b) There are no binding contracts so revenue is divided in period-byperiod bargaining post-investment. Investment can occur earlier in case (b) than in case (a) and the equilibrium in case (b) can Pareto dominate the equilibrium with binding contracts. These conclusions depend on players' discount factors.
\end{abstract}

KEYWORDS: Bargaining, Investment, Entry.

JEL C CASSIFICATION NuMBERS: C78, E22, J50, O32.

\footnotetext{
* My thanks are due to two referees for valuable and constructive criticism; to Robin Naylor and Flavio Rovida for their suggestions and comments and to seminar participants at Birkbeck, Birmingham and Warwick.
} 
Many investment decisions are made in an uncertain environment and are irreversible. Oil, coal and gas production as well as foreign direct investment provide well known examples of such decisions. Dixit (1989) has studied these decisions and has shown that a manager's optimal policy is described by a threshold: once the state of the world hits the threshold it is optimal to invest and begin production forthwith. In order to begin production, however, the manager generally employs other inputs apart from capital. This presents the owners of these factors with an opportunity to bargain with the manager over their price. By delaying agreement on price they can upset the manager's optimal investment policy so they have considerable bargaining strength. This paper assumes that both labour and capital are necessary for production it then investigates the joint determination of the timing of investment and wages when the timing of the manager's investment decision and the worker's wage are determined as an equilibrium in a bargaining game.

The model of investment in this paper is extremely simple. The firm pays a fixed cost to build a plant, drill a well or excavate a mine and after this no further investment costs are incurred. The investment generates a random flow of returns, if labour is employed, for $\mathrm{T}$ periods, where $\mathrm{T}$ can be finite or infinite, after the $\mathrm{T}$ periods are completed the investment ceases to generate any returns (the plant suddenly becomes useless $\mathrm{T}$ periods after the investment is made or the mine collapses). The random flow of returns to the investment is described by geometric Brownian motion, so in the absence of any bargaining this model closely resembles that of Dixit (1989). The main difference in this simple model of investment is that there is no exit option: once the firm has invested it is irrevocably committed to the investment for the specified time period.

In contrast to a perfectly competitive model of labour supply, used in previous work on the optimal timing of investment decisions, I will assume that there is one worker who supplies one unit of labour each period. (An alternative assumption would be that the firm produces in a unionized sector.) Before the investment takes place the manager and the worker bargain over wages, while observing the random changes in the returns to investment.

The manager is unable to pay the worker's wages without production so immediately an agreement on wages is concluded the manager pays the fixed cost of investment and production starts. Therefore, in this model the manager never agrees to a wage unless she is willing to start production, 
and never offers the worker a wage that he is willing to accept unless she is willing to start production. The payment of wages and the timing of investment are determined simultaneously.

Two specific cases are considered here: (a) there is an alternating-offer bargaining game over binding wage contracts and (b) there are no binding contracts so pre-investment wages can be renegotiated immediately after the investment. ${ }^{1}$ The two key factors operating in the models of bargaining are: the length of time a wage contract lasts and whether wage bargaining happens before or after investment. Taking these in reverse order, it is essential for wage bargaining to occur before investment if the manager is to be able to use wages to offset some of her capital expenditure, the moment she has invested it is a sunk cost and has no further impact on wage bargaining. Obviously, the duration of the pre-investment wage contract will then be important because it measures the length of time the manager can offset capital spending; the longer the wage contract the more tradeoff there is. The aim of this paper is to consider two polar cases, at both of these poles wage bargaining happens before investment but in the first case the contract length is the duration of the investment and in the second it is arbitrarily small. Thus at the first pole the manager can potentially maximize the contribution of wages towards capital spending whereas at the second this is minimized. In the case of foreign direct investment there are often permanent no- union or singleunion agreements negotiated prior to investment, so this is an example of a long-term agreement between management and labor. Examples of the other pole are very common.

If workers can commit themselves to binding wage contracts, then the manager and the workers will bargain over wage contracts before investment. ${ }^{2}$ The players' relative bargaining strengths in an alternating-offer bargaining game are usually determined by their discount factors. Here, however, a second determinant of their bargaining strength is the expected rate of change in the returns to investing, because when the players bargain over wage contracts a failure to agree a contract imposes a cost (today's revenue is lost), but it also gives a benefit as the revenue to be shared by the players grows stochastically. There is a tendency for binding wage contracts to speed investment in this model, since the manager and the worker can commit to sharing the burden of the investment

\footnotetext{
${ }^{1}$ Grout (1984) and Ulph \& Ulph (1988) have a similar taxonomy.

${ }^{2}$ Grout (1984) associates this type of wage contract with labour practices in the USA.
} 
cost and then the manager can recoup its share of the fixed cost quickly. As workers become less patient relative to the manager she is forced to bear more of the initial investment costs and chooses to delay investing because of this. As the manager becomes less patient she requires a given fixed payment to be recouped more quickly to be willing to invest hence she tends to delay investing. This means that under binding long-term wage contracts investment occurs earlier when the manager and the worker are equally patient.

When there are no long-term labour contracts the investment decision by the manager is determined mainly by the wages that will be negotiated after investment. If workers cannot commit themselves to a wage contract they must bargain each period over their share of the current revenue. 3 This inability to contract wages can delay investment and agreement in bargaining, because the manager and the worker cannot arrange to share the fixed investment costs in a binding contract. Instead, the manager must bear all of the investment costs and consequently she delays the investment until she is able to cover these. If they are impatient both manager and workers will be worse off when there are no binding wage contracts as the delay in production is so great. When players bargain period-by-period over the division of current revenue the fact that tomorrow's revenue is greater than today's need have no impact on the current bargaining outcome. Thus when they are bargaining over contracts a player's strength is determined by its discount factor and by the rate of growth of revenue, but when they are bargaining over current revenue its bargaining power is determined by its discount factor alone. It is quite possible for the workers to have much greater bargaining power when they are bargaining over a wage contract than when they are bargaining over current revenue. In these circumstances the presence of binding wage contracts delays investment. Thus below we will show that there exist parameter values where the equilibrium without binding wage contracts Pareto dominates the equilibrium in the presence of such contracts.

The last section of this paper has the worker and the manager bargaining over long-term wage contracts with period-by-period bargaining as a default option; the choice between a long-term and a short-term wage contract is endogenous. The worker's decision to commit to a wage contract is determined by how willing he is to trade off earlier production against a share in the costs of

\footnotetext{
${ }^{3}$ Grout (1984) as sociates the inability to commit to a wage contract with wage bargaining in the UK.
} 
investment. I will show that if the manager and the worker are relatively impatient and the initial prices are low, then the time of investment and the wage contract is identical to that under wage contracts. If the bargaining begins at higher initial prices then the contract agreed is increasingly influenced by the workers' preference for period-by-period bargaining, so the workers bear less of the investment costs although investment occurs earlier. If the manager and the worker are both patient, then the worker cares less about delays in production and are less willing to share in the costs of investment. Thus if he is free to choose between the various contractual arrangements and is patient then period-by-period bargaining dominates long-term contracts and investment is delayed.

The theoretical literature on wage determination and investment, or innovation, generally suggests that if workers are able to enter into binding contracts in a partial equilibrium model then investment is larger (e.g. Grout (1984) and Van Der Ploeg (1987)). Devereux and Lockwood (1991), however, have shown that if Grout's model is viewed in a general equilibrium context his conclusions may be reversed because the supply of capital can increase when binding contracts are possible. This consensus is not, however, mirrored in the empirical literature which has tended to provide equivocal results (e.g. Machin \& Wadhwani (1991a,b) or Denny \& Nickell (1991)).The first section below describes the notation needed for the model. In Section 2 the equilibrium in the game with binding contracts is described. In Section 3 the equilibrium with non-binding contracts is calculated and this is compared with Section 2. The final section calculates the equilibrium with endogenous contract choice. 


\section{A model of investment with fixed costs}

In this section I outline the structure of Dixit's (1989) model of investment with fixed costs.

There is a single discrete project (or production opportunity) that produces a flow of one unit of output. The price $\mathrm{p}_{\mathrm{t}}$ of this unit of output at time $t$ is the state variable. Time is divided into discrete periods of length $\Delta$ and numbered $0, \Delta, 2 \Delta, \ldots,$. One unit is produced so $\mathrm{p}_{\mathrm{t} \Delta}$ describes the rate of flow of revenue during the period $[\mathrm{t} \Delta, \mathrm{t} \Delta+\Delta)$, thus the total revenue received in this period is $\Delta \mathrm{p}_{\mathrm{t} \Delta}$. The evolution of $\left\{\mathrm{p}_{\mathrm{t} \Delta}\right\}_{\mathrm{t}=0}^{\bullet}$ is determined by a discrete time stochastic process which generates the uncertainty in the model. If $\mathrm{p}_{\Delta \mathrm{t}}$ is the known current value of the process, then the distribution of prices at time $\Delta \mathrm{t}+\Delta$ is a random variable that takes two values: up ${ }_{\Delta t}$ and $d_{\Delta}$ with probability $\rho$ and $1-\rho$ respectively. The parameters $\mathrm{u}, \rho, \mathrm{d}$ are determined by two parameters $\mu, \sigma>0$

$$
\mathrm{u}=\mathrm{e}^{\mathrm{\sigma} \sqrt{\Delta}}, \quad \mathrm{d}=\frac{1}{\mathrm{u}}, \quad \rho=\frac{\mathrm{e}^{\mu \Delta}-\mathrm{d}}{\mathrm{u}-\mathrm{d}} .
$$

It is known that as $\Delta \varnothing 0$ so the process $\left\{\mathrm{p}_{\mathrm{t} \Delta}\right\}_{\mathrm{t}=0}^{\bullet}$ converges to the continuous time stochastic process described by the Ito equation

$$
d p_{t}=\mu p_{t} d t+\sigma p_{t} d z_{t}
$$

where $\mathrm{z}_{\mathrm{t}}$ is Brownian motion. Thus in the limit the geometric Brownian motion price process used here is identical to that found in Dixit (1989).

There are two components to the firm's costs: a fixed investment with set up cost $\mathrm{k}$ and a flow of wage payments at the rate $\mathrm{w}$. In each period $\Delta \mathrm{t}$ the technology requires the fixed investment and one unit of labour to produce the one unit of output. Investment is irrevocable, so that once the cost $\mathrm{k}$ is paid the capital is in place for $\mathrm{T}=\mathrm{N} \Delta$ periods and it cannot be removed before this time. 4

\footnotetext{
${ }^{4}$ The justification for this is that I wish to concentrate on the ability of a partner in production to delay or accelerate entry through wage bargaining. I assume that workers cannot force the manager to continue production if the manager wishes to cease production. Thus I model a cooperative production process that requires both players' consent for output to be produced.
} 
There are two agents who participate in the project: the manager and the worker. I will refer to the manager as "she" and the worker as "he". As in Dixit (1989) the manager decides when to make the investment, she has a discount factor e $\gamma$ and aims to maximize her discounted profits. One unit of labour is supplied by the worker and he is paid wages at a constant rate w. 5 In the Dixit model there is a perfectly competitive market for labour that determines a flow payment w. Here the worker is a monopoly supplier of labour, he bargains with the manager over the wages $w$, he has a discount factor $\mathrm{e} \delta$ and he aims to maximize the discounted stream of wage payments. ${ }^{6}$

Players' are risk neutral and their payoffs are calculated by letting the time period $\Delta \varnothing 0$. If the firm were to begin production at a wage rate $\mathrm{w}$ at current prices $\mathrm{p}_{\Delta \mathrm{t}}$ then expected discounted profit as $\Delta \varnothing 0$ is given by (3). The worker's expected discounted income if it agrees to the wage $\mathrm{w}$ is given by (4) as $\Delta \varnothing 0$.
$\frac{p_{\Delta t}}{(\gamma-\mu)^{*}}-\mathrm{k}-\frac{\mathrm{w}}{\gamma^{*}}$
(4) $\frac{\mathrm{W}}{\delta^{*}}$

$\left(\right.$ Here $\gamma^{*}:=\gamma(1-\exp [-\gamma \mathrm{T}])^{-1}, \delta^{*}:=\delta(1-\exp [-\delta \mathrm{T}])^{-1}$ and $(\gamma-\mu)^{*}:=(\gamma-\mu)(1-\exp [-(\gamma-\mu) \mathrm{T}])^{-1}$ are needed to represent the finite time horizon for the investment and as T $\varnothing 8$ so $\gamma^{*} \varnothing \gamma$ etc.) The proof of this can be found in the appendix.

\section{Investment with bargaining over binding long-term wage contracts}

In this section the only possible form of wage agreement between the manager and the worker is a permanent commitment by the manager to pay wages at a fixed rate $\mathrm{w}$ and a permanent commitment by the worker to supply one unit of labour each period, case (a) above. I first describe a bargaining game over wage contracts played by the manager and the worker, then I characterise a subgame perfect equilibrium of the bargaining and investment game. I then calculate this equilibrium for the two cases $\delta=\gamma, \gamma>\delta$ and describe its properties.

\footnotetext{
${ }^{5}$ Remark 2 considers the game where the worker must also pay a fixed cost before production begins.

${ }^{6}$ An alternative assumption would be that the firm produces in a unionised sector.
} 
Once the wage contract is agreed the manager is obliged to pay wages to the worker at the contracted rate and he is obliged to provide labour, however, the firm cannot begin production until the fixed costs $\mathrm{k}$ are also paid, therefore, agreement in wage bargaining does not necessarily lead to immediate production. Here I will assume that the manager is unable to pay wages unless she is also engaged in production. ${ }^{7}$ Thus any agreement in wage bargaining must be accompanied by the manager investing. (Discussion of the solution if I relax this assumption is given in Remark 1 below.) Given this assumption it is now possible to describe play and payoffs.

Agents play an alternating offer bargaining game, as in Rubinstein (1982), over wage contracts. In period zero both players observe the current market price of output $\mathrm{p}$ ) and then the manager proposes a wage contract: $\mathrm{w}=\mathrm{w}_{0} .{ }^{8}$ The worker decides whether to accept or reject this contract. If he accepts, the manager pays workers the wage $\mathrm{w}_{0}$, she pays $\mathrm{k}$ and begins production forthwith. If the worker rejects the proposed contract then bargaining in period zero ceases and play moves to period $\Delta$. In period $\Delta$ both players observe the current price of output $\mathrm{p}_{\Delta}$, then the worker proposes a wage contract $\mathrm{w}=\mathrm{w}_{\Delta}$ and the manager must decide whether to accept or to reject this proposal. If she accepts she pays the worker at the rate $\mathrm{w}_{\Delta}$ and begins production immediately (by paying the fixed investment cost $\mathrm{k}$ ). If she rejects the offer, it is the turn of the manager to propose a wage contract at the beginning of period $2 \Delta$ (when the price $\mathrm{p}_{2 \Delta}$ is first observed). Bargaining continues with alternating proposers until an offer is first accepted and then bargaining ceases. If the bargaining continues indefinitely and never reaches an agreement then both players receive a payoff of zero. Suppose instead that the bargaining reaches agreement in period $\Delta t$ at price level $\mathrm{p}_{\Delta \mathrm{t}}$ and a wage rate $\mathrm{w}$, then the manager begins production immediately by the above assumption. The expected payoffs of the players given agreement at $\mathrm{p}_{\Delta \mathrm{t}}$ is defined to be (3) for the manager's discounted expected profit and (4) for the worker's discounted wage. (Thus I assume that the limit as $\Delta \varnothing 0$ is also the payoff in the discrete time game.)

\footnotetext{
${ }^{7}$ This could be justified by an assumption on credit markets.

${ }^{8}$ The equilibrium calculated will only consider the case where $\Delta \varnothing_{0}$, so the worker can make a counter offer immediately and manager has no advantage from moving first.
} 
I now describe a stationary subgame perfect equilibrium of bargaining game above (that is a subgame perfect equilibria of the game where players use strategies which depend only on the current state $\mathrm{p}_{\Delta \mathrm{t}}$ ). I only study the stationary equilibria of the game where players use strategies that depend only on the current state. Remark 3 below explains how non-stationary equilibria can be calculated and provides conditions for the stationary equilibrium to be the unique subgame perfect equilibrium of this game. First I will need some additional definitions: let $\alpha(p)$ ( respectively $\beta(p)$ ) be the manager's ( respectively worker's) expected payoff at a stationary equilibrium of the game if the current price is $\mathrm{p}$ and it is the manager's ( respectively worker's) turn to propose a contract. Result 1 on the relationship between $\alpha$ and $\beta$ was proved in Cripps (1994). (If $\mathrm{f}(\mathrm{p}$ ) is defined on $R_{+}$let $\Pi_{p} f$ ( respectively $\Pi_{p} 2 f$ ) to be the expected value of $f($.$) in one ( respectively two) period(s)$ given today's price is $p$, that is; $\Pi_{p} f:=\rho f(u p)+(1-\rho) f(d p), \quad \Pi_{p} 2 f:=\rho^{2 f}\left(u^{2} p\right)+2 \rho(1-\rho) f(p)+$ $\left.(1-\rho)^{2} \mathrm{f}(\mathrm{d} 2 \mathrm{p}).\right)$

Result 1: The $\alpha$ is the smallest solution to (5) and $\beta$ is the smallest solution to (6)

$$
\begin{aligned}
& \alpha(\mathrm{p})=\max _{1}^{\prime} \frac{\mathrm{p}}{(\gamma-\mu)^{*}}-\mathrm{k}-\frac{\delta^{*}}{\gamma^{*}} \mathrm{e}^{-\Delta \delta} \Pi_{\mathrm{p}} \beta, \mathrm{e}^{-2 \Delta \gamma \Pi_{\mathrm{p}}^{2} \alpha}, \\
& \beta(\mathrm{p})=\max _{1}^{\prime} \frac{\gamma^{*}}{\delta^{*}}\left(\frac{\mathrm{p}}{(\gamma-\mu)^{*}}-\mathrm{k}\right)-\frac{\gamma^{*}}{\delta^{*}} \mathrm{e}^{-\Delta \gamma} \Pi_{\mathrm{p}} \alpha, \mathrm{e}^{-2 \Delta \delta} \Pi_{\mathrm{p}}^{2} \beta
\end{aligned}
$$

The proof is in Cripps (1994) and the following argument describes its steps. When the manager proposes the wage in state $\mathrm{p}$ the worker would accept the wage if she offers more than the equilibrium payoff from waiting $\Delta$ periods. The worker would thus accept the wage $\mathrm{w}$ if $\mathrm{w}=\delta^{*} \mathrm{e}-$ ${ }^{\delta} \Pi_{\mathrm{p}} \beta$. In equilibrium the manager faces a choice between making an offer that is accepted and getting $\mathrm{p}\left[(\gamma-\mu)^{*}\right]^{-1}-\mathrm{k}-\left(\delta^{*} / \gamma^{*}\right) \mathrm{e}^{-} \delta \Delta \Pi_{\mathrm{p}} \beta$, or waiting one period. If she waits the game moves to state $q$ and the worker will offer the manager at most e $-\gamma \Delta \Pi_{q} \alpha$ (the most she could get by rejecting his offer in state q). Thus the manager must choose between making an initial acceptable offer, or waiting two periods and getting an expected payoff

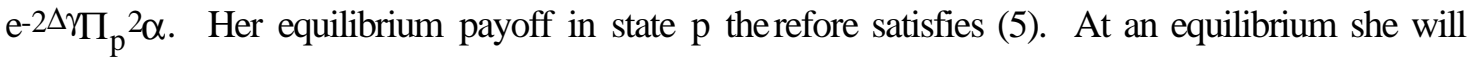
choose the optimal time to make an acceptable offer to the worker. This can be described as a one person optimal stopping problem with a reward function $\mathrm{p}\left[(\gamma-\mu)^{*}\right]-1-\mathrm{k}-\left(\delta^{*} / \gamma^{*}\right) \mathrm{e}-\delta \Delta \Pi_{\mathrm{p}} \beta$ in state 
p. By Dynkin (1960) it follows that $\alpha(\mathrm{p})$ is the smallest function satisfying (5) given $\beta$. To describe how the worker and the manager actually bargain I must solve (5) and (6).

I begin with the case $\delta=\gamma$ where the worker is more impatient than the manager. I will calculate a equilibrium of the bargaining game as $\Delta \varnothing 0$. The equations (7)-(11) below define the equilibrium payoffs $\alpha(p), \beta(p)$ and the parameters $\lambda, \phi, a, b, \pi$ are needed to describe the equilibrium. The equilibrium payoffs $\alpha, \beta$ have a critical value $\pi$. The first time $\mathrm{p}_{t}=\pi$ (which is random because $\mathrm{p}_{\mathrm{t}}$ is random) is the point at which bargaining finishes and investment occurs. The payoffs $\alpha, \beta$ are shown in Figure 1 as the unbroken lines. The three broken lines will be used in the proof of the proposition.

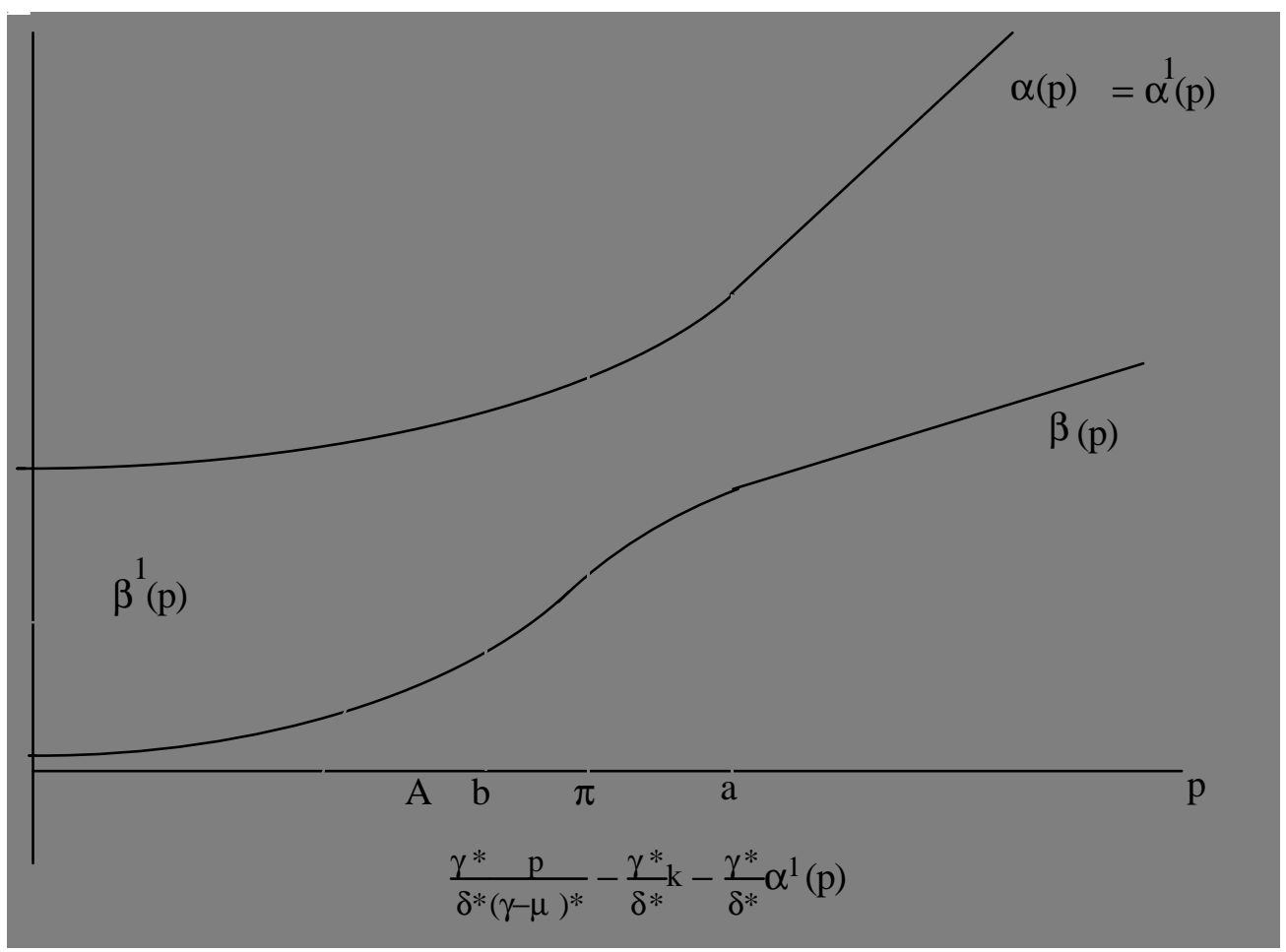

Figure $1(\gamma=\delta)$

At the equilibrium the firm will choose to invest at the threshold level of prices $\pi$, defined by (9), although the manager is indifferent between investing when $p_{t}=\pi$ and later when $p=a$. She is indifferent happens because the worker is the impatient partner in the bargaining and he encourages 
the manager to invest at the lower price level $\pi$ by offering her an attractive wage bargain. The wage bargain offered by the worker is just sufficient to induce her to invest at this earlier time. The equilibrium wage contract requires the more patient of the two players to bear most of the fixed costs of investment; in (10) as $\delta$ becomes large the manager pays the complete fixed cost $\mathrm{k}$. This happens because, impatient players need greater immediate compensation to cover the fixed cost of investment, so an efficient bargain will specify that the more patient of the players bears most of the investment costs. The expected payoff to the manager is not independent of its opponent's impatience. As $\delta$ becomes larger she has greater power in the bargaining, so she pays lower wages. However, a conflicting effect arises because as the worker becomes more impatient she bears more of the investment costs. The sum of these two effects, as $\delta$ becomes large, is that the investment costs dominate and this reduces her expected profits prior to investment (in (10) the coefficient on $\mathrm{p}^{\lambda}$ decreases in $\delta$ ). It will also lead her to defer her optimal investment time (a increases in $\delta$ ). (If the game begins at a very high price where there is immediate investment the bargaining power of the manager dominates and her expected payoff is increasing in $\delta$.)

As the worker becomes more impatient so he prefers $\pi$ to be smaller and he offers the manager more favourable wage contracts to get earlier investment. However, from above the increase in $\delta$ leads the manager to want to defer investment which runs counter to the worker's interests. Some arithmetic reveals that $(\pi / \mathrm{a}) \varnothing 1$ as $\delta$ becomes large, thus although he prefers earlier investment his very weakness forces him to conform to the manager's wishes. In the limit a very myopic worker will offer a wage contract that induces the manager to invest the moment his expected payoff from investment becomes positive (at the point $\mathrm{A}$ in the figure above) which approaches a. For prices less than 'a' he receives a zero expected payoff.

Proposition 1: If $\delta=\gamma>\mu$ and $\Delta \varnothing 0$, the bargaining game with binding contracts has a stationary subgame perfect equilibrium with state dependent expected payoffs $\alpha(\mathrm{p}), \beta(\mathrm{p})$ in (10) and (11). At this equilibrium bargaining ceases and investment occurs the first time $\mathrm{p}_{\mathrm{t}}=\pi$. Where $\pi$ is the smallest positive solution to (9). 
(7) $\lambda=\left(\frac{1}{2}-\frac{\mu}{\sigma^{2}}\right)+\sqrt{\left(\frac{1}{2}-\frac{\mu}{\sigma^{2}}\right)^{2}+\frac{2 \gamma}{\sigma^{2}}} \quad \phi=\left(\frac{1}{2}-\frac{\mu}{\sigma^{2}}\right)+\sqrt{\left(\frac{1}{2}-\frac{\mu}{\sigma^{2}}\right)^{2}+\frac{2 \delta}{\sigma^{2}}}$

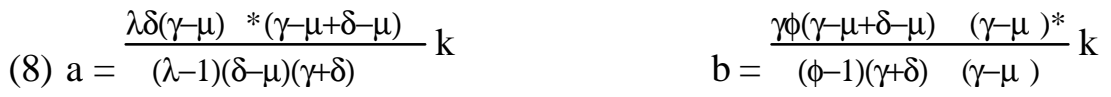

(9) $\lambda \phi(\gamma-\mu)^{*} \mathrm{k}=\lambda(\phi-1) \pi-(\delta-\mu)(\phi-\lambda)(\gamma-\mu+\delta-\mu)^{-1} \mathrm{a}^{1-\lambda} \pi^{\lambda}$

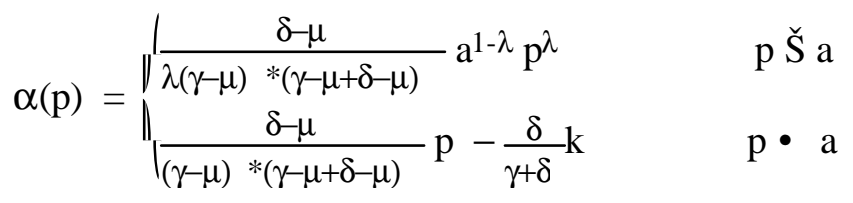

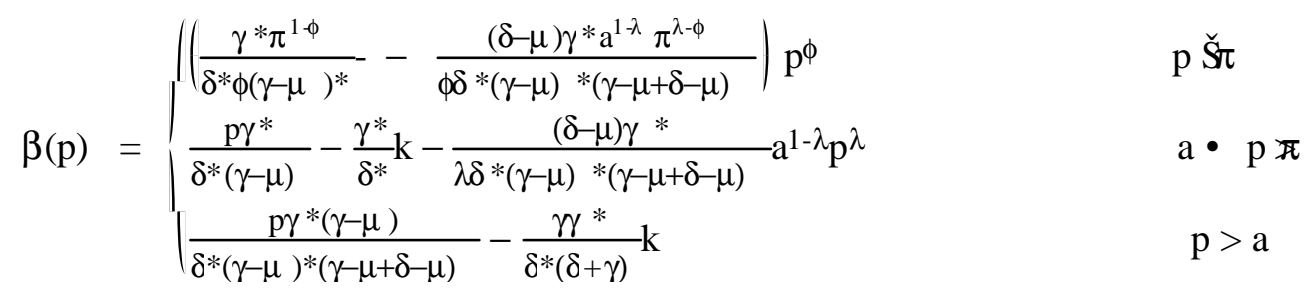

Proof: See Appendix.

If $\gamma>\delta$ manager has little bargaining strength and she is also slow to invest because she waits until prices are high so that she quickly covers the fixed costs of investment. The equilibrium described in Proposition 2 has a threshold value for prices $\theta$ that is determined by (12). The firm starts production when the price level first reaches the level $\theta$, but at $p=\theta$ the manager strictly prefers to start production although the worker is indifferent between this and waiting until $p_{t}=b>\theta$. Thus she is offering a sufficiently favourable wage bargain to just induce him to agree earlier. As she becomes less patient the worker encourages investment by demanding less revenue, thus offering the manager earlier compensation for the investment costs. But as $\gamma \varnothing 8$ the worker must accept very low wages to ensure investment, so in (8) and (12) we see that as $\gamma$ increases both thresholds $b$ and $\theta$ become arbitrarily large. 
If $\gamma>\delta$ the worker has greater bargaining strength than the manager, but because the manager is reluctant to pay the fixed investment costs his ability to demand higher wages after investment is tempered by an increasing need to offset her investment costs. Examination of the coefficient on $\mathrm{p}^{\phi}$ in (14) shows us that as $\gamma$ increases so $b$ becomes large and payoffs at any given price less than $b$ tend to zero. Thus again the effect of the fixed investment costs dominate any benefit from increased bargaining strength on his payoffs. The manager's payoffs at the equilibrium $\alpha$ are given by (13) and it is clear that as $\gamma$ increases she bears proportionately less of the fixed investment costs. 
Proposition 2: If $\gamma=\delta>\mu$ and $\Delta \varnothing 0$ then the bargaining game with binding contracts has a stationary subgame perfect equilibrium with state dependent expected payoffs $\alpha(\mathrm{p}), \beta(\mathrm{p})$ in (13),(14). At this equilibrium bargaining ceases and investment occurs the first time $\mathrm{p}_{\mathrm{t}}=\theta$, where $\theta$ is the smallest positive solution to (12).

$$
\begin{aligned}
& \phi(\lambda-1)(\gamma-\mu+\delta-\mu) \theta-(\lambda-\phi)(\gamma-\mu) * b 1-\phi \theta \phi=k \lambda \phi(\gamma-\mu)(\gamma-\mu+\delta-\mu)
\end{aligned}
$$

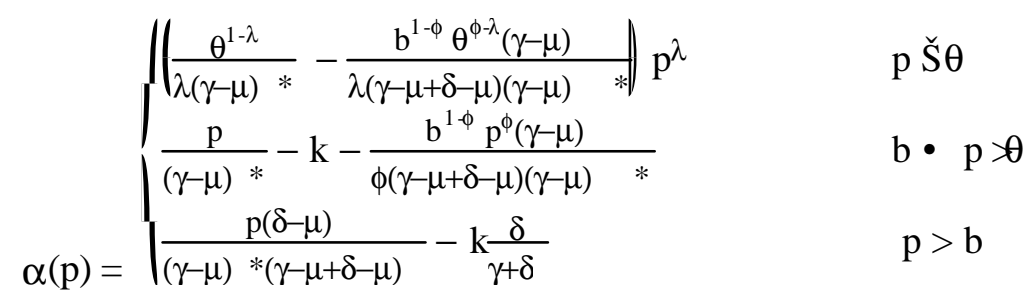

$$
\begin{aligned}
& \mid \frac{\gamma}{\phi \delta(\gamma-\mu+\delta-\mu)} b^{1-\phi} \mathrm{p}^{\phi} \quad \mathrm{p} \check{\mathrm{S}} \mathrm{b} \\
& \beta(p)=\mid \frac{\gamma}{\delta(\gamma-\mu+\delta-\mu)} p-\frac{\gamma^{2}}{\delta(\gamma+\delta)} k \quad \quad p>b
\end{aligned}
$$

Proof: This is symmetric with the proof of Proposition 1.

\section{Remark 1}

What happens if I relax the above assumption and allow the firm to delay investment beyond the time wages are agreed? If the manager is more patient than the worker then there is generally immediate agreement on wages but delay in investment. Thus the manager offers the impatient workers insurance against the delay before production and is able to pay a lower wage in return. This insurance feature of long-term wage contracts is examined more carefully in Bester (1989). However, if the worker is more patient than the manager this will not happen because the manager is the least patient of the two players and the worker cannot offer the manager similar insurance, so instead agreement and investment happen at the same time and the solution given above applies in this case. 


\section{Remark 2}

It is quite possible to generalise this solution to the case where the worker also pays a fixed cost when the firm begins production. Such a cost could arise if the worker needs to engage in some technique-specific training or also make an investment. In this case two types of cross-subsidisation happen; both worker and manager would be able to offset their fixed costs against future revenue.

\section{Remark 3}

Throughout this section we have calculated a stationary subgame perfect equilibrium, the reader may justifiably wonder whether this game has other equilibria. Let $a(p)(b(p))$ be the manager's (worker's) worst equilibrium payoff if she (he) is proposer in state $\mathrm{p}$, also let $\mathrm{A}(\mathrm{p})(\mathrm{B}(\mathrm{p}))$ be the manager's (worker's) best equilibrium payoff if she (he) is proposer in state p. Now by considering the properties of the best and worst equilibrium payoffs the pair $(a(p), B(p))$ and the pair $(A(p), b(p))$ must also satisfy the equations (5) and (6) replacing $\alpha$ with a or A where appropriate and $\beta$ with B or b. Thus if (5) and (6) have a unique solution then so does the bargaining game have a unique subgame perfect equilibrium which is identical to the stationary equilibrium described in this section. The proof of Proposition 1 establishes that $\alpha(\mathrm{p}), \beta(\mathrm{p})$ are the unique twice continuously differentiable solution to (5),(6), however, the uniqueness of the solution in a larger class of functions is a technical issue that is beyond the scope of this paper.

\section{Investment without binding long-term wage contracts}

I now examine a second case where the worker cannot commit himself to a long-term wage contract, so in addition to bargaining before investment the worker and the manager will choose to renegotiate wages in every period after the investment has taken place. The absence of contracts means that the players can only bargain over the division of current revenue and I will assume that this bargaining over current revenue is completed very quickly. This section begins with a description of the game, then the equilibrium is calculated. Finally I compare the equilibrium here with that found in Section 2. These comparisons will show that the speed of investment under the 
two different regimes admits no simple ranking: investment can occur later if there are no binding wage contracts, but can also occur sooner. I will also show that the equilibrium in the presence of binding wage contracts can Pareto dominate the equilibrium without binding contracts and vice versa the equilibrium without binding contracts can Pareto dominate the equilibrium with contracts. If there are no great inequalities in discounting and players are not very patient then both players are better off in the presence of long-term wage contracts. On the other hand if the worker is patient and $\mathrm{T}$ is large then both players are better off if they are unable to commit themselves to long-term contracts.

The order of play is as follows: in period zero both players observe $\mathrm{p}_{0}$ and the manager then proposes a wage rate $\mathrm{w}$ for the period $[0, \Delta)$ which is equivalent to a division of the current revenue $\Delta \mathrm{p}_{0}$ the worker then decides whether to agree to this wage rate and then the manager decides whether to invest then play moves to period $\Delta$. This sequence of decisions is repeated, with alternating proposers, in every period before investment occurs. Once the investment has been made the sequence of decisions is replaced by bargaining at time $\Delta$ t over the division of the current revenue $\Delta \mathrm{p}_{\Delta \mathrm{t}}$. The bargaining in period $\Delta \mathrm{t}$ over the revenue $\Delta \mathrm{p}_{\Delta \mathrm{t}}$ will not be specified. We will assume that the speed of this bargaining is very rapid indeed and that a generalised Nash bargaining solution gives the manager a share $\delta /(\gamma+\delta)$ of the revenue $\Delta \mathrm{p}_{\Delta \mathrm{t}}$ and the worker a share $\gamma /(\gamma+\delta)$. Players' weights in the generalised bargaining solution are determined by their relative discount factors alone. 9 This in effect assumes that the bargaining over a short run wage proceeds at a much faster rate than the changes in prices and bargaining over binding wage contracts in the previous section. The important feature of the bargaining over current revenue is that this is not affected by the stochastic rate of growth of revenue, so delay in the current bargaining round is costly because some output is lost, but does not yield benefits from delay.

\footnotetext{
${ }^{9}$ It is possible to provide a non-cooperative underpinning for the use of the generalised Nash bargaining solution here by allowing an alternating offer bargaining game within the period $\Delta \mathrm{t}$. Divide the period $[\Delta \mathrm{t}, \Delta \mathrm{t}+\Delta)$ into a sequence $\Delta t+\Delta(1-\chi), \Delta t+\Delta\left(1-\chi^{2}\right), \Delta t+\Delta\left(1-\chi^{3}\right), \ldots$, where $\chi<1$. In each of these smaller periods there is a flow of revenue which is lost if no production happens, so at time $\Delta t+\Delta\left(1-\chi^{\mathrm{n}}\right)$ there is only potential revenue $\chi^{\mathrm{n}} \Delta \mathrm{p} \Delta \mathrm{t}$. Calculate the subgame perfect equilibrium of the alternating offer bargaining game over these smaller periods and let $\chi \varnothing_{0}$. As the cake shrinks at the rate $\chi$ it is players' relative discount factors that will determine the division of reveune and this equals the sharing rule given above.
} 
When the manager has invested, given the above model of post-investment bargaining, she can treat the worker as a passive entity that simply asks for a wage $\Delta \mathrm{p}_{\Delta t} \gamma /(\gamma+\delta)$ in state $\mathrm{p}_{\Delta \mathrm{t}}$. Her discounted expected payoff from period $(\mathrm{t}+1) \Delta$ when she invested in period $t \Delta$ is, by the result in the Appendix, therefore

$$
\frac{\delta}{\gamma+\delta} \frac{\mathrm{p}_{\Delta(\mathrm{t}+1)}}{(\gamma-\mu)^{*}}-\mathrm{k}, \quad \text { as } \Delta \rightarrow 0
$$

By taking limits here we have approximated the payoff in the discrete time game described above with the continuous time limits. This is consistent with the procedure adopted in the previous section. Since the stopping times in the discrete case do converge to their continous time analogues provided $\Delta$ is sufficiently close to zero the calculations made here are arbitrarily good approximation to the true dscrete time outcome.

The manager's expected payoff before investing may be differ from this because the wage rate $\mathrm{w}_{\Delta \mathrm{t}}$ for the period $[\mathrm{t} \Delta,(\mathrm{t}+1) \Delta)$ when investment happens has not been determined. I will argue that there are two natural bounds on $\mathrm{w}_{\Delta \mathrm{t}}$, the first is that $\mathrm{w}_{\Delta \mathrm{t}}=0$ so the manager cannot force the worker to buy his job (or equivalently the manager cannot require the worker to make an explicit lump-sum contribution to the cost of the investment) this seems appropriate if the worker has limited access to capital markets and so is unable to borrow against future earnings. An upper bound on $\mathrm{w}_{\Delta \mathrm{t}}$ arises because the manager is never willing to pay a wage so large that her expected profit during period $\Delta \mathrm{t}$ is zero, because otherwise the manager could simply invest in period $\mathrm{t} \Delta$ without agreement in on wages and wait until period $\Delta(\mathrm{t}+1)$ before bargaining with the worker. The upper and lower bound on $\mathrm{w}_{\Delta \mathrm{t}}$ imply that as $\Delta \varnothing 0$ the manager's discounted expected profit from investing in period $\Delta$ converges to $\delta(\gamma+\delta)^{-1} \mathrm{p}_{\Delta \mathrm{t}}(\gamma-\mu)^{*-1}-\mathrm{k}$ whatever actual wage rate reigns in period $\mathrm{t} \Delta$. To sum up because there is an arbitrarily short period for the pre-investment wage to be paid and the preinvestment wage rate is bounded as $\Delta \varnothing 0$ the expected profit of the manager from investing is determined solely by the expected profit post-investment.

Proposition 3 describes the equilibrium in this game. As $\Delta \varnothing 0$ her optimal time for investment is given by a threshold value $\mathrm{c}$ (defined in (15)) such that she invests the first time $\mathrm{p}_{\Delta \mathrm{t}}=\mathrm{c}$. She bears all 
of the cost of investment, so the only effect of an increase in $\delta$ is to reduce the future wage bill which brings forward her optimal time of investing. An increase in $\delta$, therefore, unambiguously increases her equilibrium expected profits $\xi(p)$, defined in (16). The effect of an increase in $\delta$ on the worker's equilibrium expected wages $\zeta(\mathrm{p})$ (defined in (17)) is ambiguous because it reduces his wage but hastens investment. In fact as $\delta$ becomes large it is clear that his expected wage tends to zero (recall that as $\delta$ increases so does $\phi$ ). However, if $\mathrm{c}$ is sufficiently small, both players are sufficiently patient and prices are close to zero, then it is possible for his payoff, $\zeta(\mathrm{p})$, to improve as $\delta$ rises. ${ }^{10}$ In this case his benefits from earlier investment outweigh the reduction in wages. An increase in the manager's impatience $(\gamma)$ always reduces her payoffs (an increase in $\gamma$ reduces her share of profit and delays the time of investment). The effect on the worker's payoffs is not clear but again as $\gamma$ becomes large the investment of the firm is delayed and the expected wage tends to zero.

Proposition 3: If $\Delta \varnothing 0, \gamma, \delta>\mu$ and there are no binding contracts, then the manager invests when the price first reaches the level c and the manager's (respectively worker's) payoffs in state $\mathrm{p}$ are $\xi(\mathrm{p})($ respectively $\zeta(\mathrm{p}))$.

$$
\begin{aligned}
& c=\left(\frac{k \lambda}{\lambda-1}\right)\left(\frac{\gamma+\delta}{\delta}\right)(\gamma-\mu) *
\end{aligned}
$$

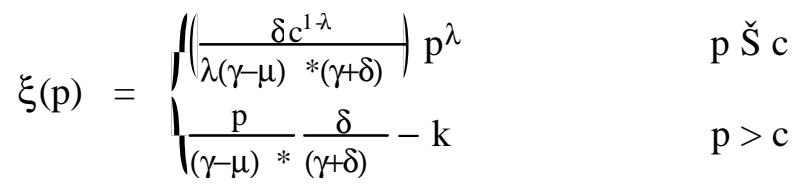

$$
\begin{aligned}
& \zeta(\mathrm{p})= \begin{cases}\left.\mid \frac{\gamma \mathrm{c}^{1-\phi}}{(\delta-\mu) *(\gamma+\delta)}\right) \mathrm{p}^{\phi} & \mathrm{p} \check{S} \mathrm{c} \\
\frac{\mathrm{p}}{(\delta-\mu) * \frac{\gamma}{(\gamma+\delta)}} & \mathrm{p}>\mathrm{c}\end{cases}
\end{aligned}
$$

Proof : The manager has to decide what is the best time to invest and to receive the expected profits $\delta \mathrm{p}_{\Delta \mathrm{t}}(\gamma-\mu)^{*-1}(\gamma+\delta)^{-1}-\mathrm{k}$. As $\Delta \varnothing 0$ this approaches the problem of stopping geometric

\footnotetext{
${ }^{10}$ This occurs as $(\mathrm{p} / \mathrm{c})^{\phi-1}$ has a derivative with respect to $\phi$ that approaches 8 as $\mathrm{p}$ tends to zero.
} 
Brownian motion with a linear reward. Following Øksendal (1992) the solution, $\xi(\mathrm{p})$, to the manager's optimisation is described by (15) and (16). Once she invests $\left(\mathrm{p}_{\mathrm{t}}=\mathrm{c}\right)$ the worker receives $\Delta \mathrm{p} \gamma /(\delta+\gamma)$ in each period, thus his expected discounted wage, as $\Delta \varnothing 0$, is $\mathrm{p} \gamma(\delta-\mu)^{*-1}(\gamma+\delta)^{-1}$. For $\mathrm{p}<\mathrm{c}$ the worker's expected payoff satisfies the condition $\zeta(\mathrm{p})=\mathrm{e}-\delta \Delta \Pi_{\mathrm{p}} \zeta$ because he is waiting for the firm to invest. As $\Delta \varnothing 0$ this implies $\zeta(\mathrm{p})$ satisfies

$$
\left(\sigma^{2 / 2}\right) \mathrm{p} 2 \zeta^{\prime \prime}+\mu \mathrm{p} \zeta^{\prime}-\delta \zeta=0
$$

(This can be obtained by taking a 2nd order Taylor Series approximation to $\zeta(\mathrm{up})$ and $\zeta(\mathrm{dp})$.) Ruling out the possibility that $\zeta(\mathrm{p}) \mid \varnothing 8$ as $\mathrm{p} \varnothing 0$, the solution to (18) gives $\zeta(\mathrm{p})=\mathrm{Dp} \phi$ and $\mathrm{D}$ is determined by the continuity of $\zeta$ at $\mathrm{p}=\mathrm{c}$.

Q.E.D.

I now give a result on the relationship between the model where players bargain over contracts and the model where players are unable to make commitments. I show that if $\delta=\gamma$, or if $\gamma \varnothing 8$, then investment in the contracting case occurs earlier than in the non-contracting case, hence for this class of models investment occurs sooner when contracts are possible. The intuition for this again follows from the treatment of the investment costs. In the no contracting case the manager always pays the fixed investment $\mathrm{k}$, as the worker has no credible means of sharing this cost, and the manager does not invest until she expects to be able to recoup its entire outlay from her own incomes. If there are contracts, however, the worker can accept lower wages to compensate the manager for her investment costs, thus the condition for investment is that the manager expects to recoup her investment cost from her (larger) future shares in the firm's revenues.

Proposition 4 also shows that there is a class of models where investment is delayed longer when players bargain over binding wage contracts than when they bargain period-by-period. For these models the threshold price that triggers investment when there are no contracts $\left(p_{t}=c\right)$ is strictly lower than the threshold price that triggers investment when there are contracts $\left(p_{t}=\theta>c\right)$. The models which give this result have a worker that is more patient than the manager $(\delta<\gamma)$ and have $\delta$ approaching $\mu$. The explanation for the early investment is that as $\delta$ approaches $\mu$ there is a 
differential effect on pre- and post-investment bargaining. As $\delta \varnothing \mu$ in the period-by-period bargaining after investment so the worker's bargaining power converges to $\gamma(\mu+\gamma)-1>0.5$ which is bounded away from unity. However, as $\delta \varnothing \mu$ in the bargaining over long-term wage contracts before investment his bargaining strength approaches unity. In the bargaining over long-term contracts before investment the expected rate of growth of revenue is $e^{\mu \Delta}$ and as $\delta$ approaches $\mu$ his discount factor $\left(\mathrm{e}^{-} \delta \Delta\right)$ multiplied by the rate of growth approaches unity. In effect the worker's costs of delay tends to zero. Thus as $\delta$ tends to $\mu$ the worker experiences no costs of delay and has all the bargaining power. This means that the manager receives a very small share of postinvestment revenue so she must wait until prices are very high before she is able to recoup the costs of investment.

Proposition 4: (a) If $\delta=\gamma$ or if $\gamma \varnothing 8$ then investment in models with long-term contracts occurs earlier than in models without long-term contracts: $\pi<\mathrm{c}$. (b) If $\gamma>\delta, \delta$ is sufficiently close to $\mu$, and $\mathrm{T}$ is large then investment is delayed longer in the presence of long-term contracts than it is in the presence of period-by-period bargaining; $\theta>\mathrm{c}$.

Proof: To show $\pi<\mathrm{c}$ when $\delta=\gamma>\mu$ it is sufficient to show that a $<$, that is

$$
\mathrm{k} \frac{\lambda}{\lambda-1} \frac{\gamma+\delta}{\delta}(\gamma-\mu) *>\mathrm{k} \frac{\lambda}{\lambda-1} \frac{\delta}{\gamma+\delta} \frac{(\gamma-\mu) *}{(\delta-\mu)}(\gamma-\mu+\delta-\mu)
$$

Re-arranging this gives $\gamma \delta(\gamma+\delta)>\mu\left(\gamma^{2}+2 \gamma \delta-\delta 2\right)$, which always holds if the right is negative. If the right is positive and $\mu=\gamma$ then the right side is maximized when $\mu=\gamma$ and it is simple to verify that the inequality holds. As $\gamma \varnothing 8$ so $\lambda \varnothing 8$ and $c>b$, but by construction $b>\theta$ hence $c>\theta$.

To show that $\mathrm{c}<\theta$ as $\delta$ approaches $\mu$ I will show that $\mathrm{p}(\gamma-\mu)^{*-1-k-\beta(p)}$ is negative when $\mathrm{p}=\mathrm{c}$, so the manager would never agree to a binding wage contract when $\mathrm{p}=\mathrm{c}$. First $\mathrm{c}<\mathrm{b}$ iff

$$
1>\frac{\lambda}{\lambda-1} \frac{\phi-1}{\phi} \frac{(\gamma+\delta)^{2}}{\gamma \delta} \frac{\gamma-\mu}{\gamma-\mu+\delta-\mu}
$$

and as $\delta \varnothing \mu$ so $\phi \varnothing 1$, thus by choosing $\delta$ sufficiently close to $\mu$ it is true that $\mathrm{c}<\mathrm{b}$. $\beta$ (c) can now be calculated. Thus $[\mathrm{c}(\gamma-\mu) *-1-\mathrm{k}-\beta(\mathrm{c})] / \mathrm{c}<0$ if and only if 


$$
\left(\frac{\phi \delta}{\gamma}\right)\left(\frac{\gamma-\mu+\delta-\mu}{(\gamma-\mu)^{*}}\right)\left(\frac{\gamma \lambda+\delta}{\lambda(\gamma+\delta)}\right)<\left(\frac{c}{b}\right)^{\phi-1}
$$

As $\delta \varnothing \mu$ so $\phi \varnothing 1$, by (7), and the right hand side above converges to unity whereas the left converges to less than unity as $\delta \varnothing \mu$ if T is sufficiently large.

Q.E.D.

Proposition 5 shows that if the manager and the worker have the same discount factors and are both impatient, then they are both better off if they can write contracts. To do this calculation we assume that the initial price $\mathrm{p}_{0}$ is sufficiently low for the firm not to invest immediately, but for some waiting to be optimal. On the other hand it shows that if the worker is more patient than the manager $(\delta<\gamma)$ and $\delta$ is close to $\mu$, then both players are better off if they cannot write binding contracts. Again to do this calculation we assume prices are sufficiently low for there to be some delay before investment.

Proposition 5 : (a) If the manager and the worker have equal rates of time preference, $\phi=\lambda>2$ and $\mathrm{p}_{0}=\mathrm{a}<\mathrm{c}$ then the equilibrium with binding contracts Pareto dominates the equilibrium without them. (b) If $\mathrm{p}_{0}<\mathrm{c}, \mathrm{T} \mu(\gamma-\mu)>(\gamma+\mu)$ and the worker is more patient than the manager then the equilibrium without binding contracts Pareto dominates the equilibrium with binding contracts as $\delta \varnothing \mu$.

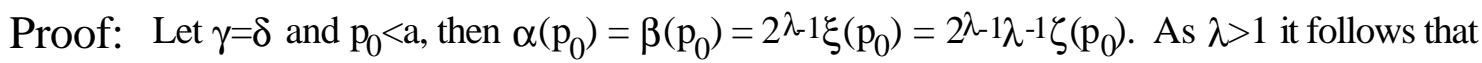
$\xi\left(\mathrm{p}_{0}\right)<\alpha\left(\mathrm{p}_{0}\right)$. Also, $\lambda^{-1} 2^{\lambda-1}=1$ iff $\lambda=1$ or $\lambda=2$, so $\zeta\left(\mathrm{p}_{0}\right)<\beta\left(\mathrm{p}_{0}\right)$ for $\lambda>2$.

Let $\gamma>\delta$ and $\mathrm{p}<\mathrm{p}_{0}$, then $\xi(\mathrm{p})>\alpha(\mathrm{p})$ iff

$$
\left.\frac{\delta}{\gamma+\delta}>\left(\frac{c}{\theta}\right)^{\lambda-1}\right)^{\prime} 1-\left(\frac{\theta}{b}\right)^{\phi-1}\left(\frac{\gamma-\mu}{\gamma-\mu+\delta-\mu} \|_{\nu}^{\|}\right.
$$


As $\delta \varnothing \mu$ so $\phi \varnothing 1$ and $(\theta / b) \phi-1 \varnothing 1$ thus inequality (19) holds for $\delta$ sufficiently small. If $\mathrm{p}<\mathrm{p}_{0}$ then $\zeta(\mathrm{p})>\beta(\mathrm{p})$ iff

$$
\frac{\phi \delta(\gamma-\mu+\delta-\mu)}{(\delta-\mu) *(\gamma+\delta)}>\left(\frac{g}{b}\right)^{\phi-1}
$$

As $\mathrm{T} \mu(\gamma-\mu)>(\mu+\gamma)$ as $\delta \varnothing \mu$ this inequality is satisfied.

Q.E.D.

\section{Investment with bargaining and endogenous contract choice}

In this section I abandon the assumption of Sections 2 and 3 that the type of contract is determined by institutional factors outside the model and consider what happens if the choice between a binding wage contract and period-by-period bargaining is endogenous. Below I will treat period-by-period bargaining as a default option which the manager of the firm can implement by unilaterally making the investment. I will then provide a thumbnail sketch of the equilibria in two different sets of circumstances.

With period-by-period bargaining as a default option the equations (5) and (6) defining the equilibrium payoffs no-longer apply. Define $\varphi(p)$ and $\kappa(p)$ to be the manager's and worker's expected payoff in state $\mathrm{p}$ at a stationary perfect equilibrium of the game with endogenous contract choice. The equilibrium payoffs $\varphi(p), \kappa(p)$ satisfy

$$
\begin{aligned}
& \varphi(p)=\max _{1}^{\prime \prime} \frac{\mathrm{p}}{\gamma-\mu}-\mathrm{k}-\frac{\delta}{\gamma} \mathrm{e}^{-\Delta \delta} \Pi_{\mathrm{p}} \kappa, \mathrm{e}^{-2 \Delta \gamma} \Pi_{\mathrm{p}}^{2} \varphi, \xi(\mathrm{p}) \\
& \kappa(\mathrm{p})=\max _{1}^{\prime} \frac{\gamma}{\delta}\left(\frac{\mathrm{p}}{\gamma-\mu}-\mathrm{k}\right)-\frac{\gamma}{\delta} \mathrm{e}^{-\Delta \gamma} \Pi_{\mathrm{p}} \varphi, \mathrm{e}^{-2 \Delta \delta} \Pi_{\mathrm{p}}^{2} \kappa, \zeta(\mathrm{p})
\end{aligned}
$$

where $\xi(\mathrm{p})$ and $\zeta(\mathrm{p})$ are the functions defined in Section 3. The manager faces the choice between

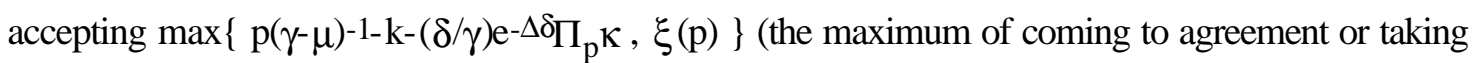


the outside option) or waiting two periods; in equilibrium it will choose the best of these two possibilities. I now sketch the type of solution observed in various cases.

\section{Case One : $\gamma=\delta$ and $\lambda>2$}

By Proposition 5 the equilibrium with period-by-period bargaining $(\xi(\mathrm{p}), \zeta(\mathrm{p}))$ is Pareto dominated by the binding contracts solution $(\alpha(\mathrm{p}), \beta(\mathrm{p}))$ if $\mathrm{p}<\pi$. These functions are shown in the figure below.

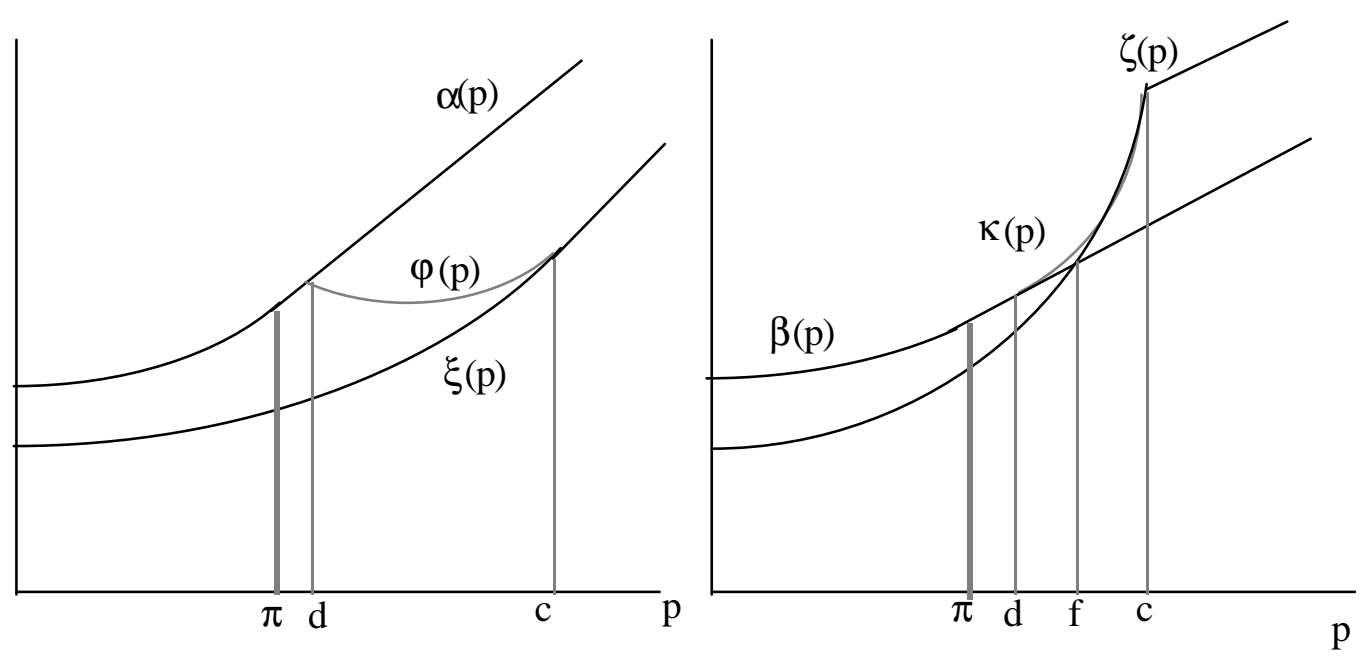

Figure 2

However, as prices $\mathrm{p}$ get sufficiently large (p>f) the worker prefers $\zeta(\mathrm{p})$ to $\beta(\mathrm{p})$. This is because under period-by-period bargaining the worker is not forced to pay a share of the investment costs $\mathrm{k}$ so he bears less costs in $\zeta(\mathrm{p})$ and the time until prices reach the trigger point $\mathrm{c}$ is sufficiently small for the expected payoff $\zeta(\mathrm{p})$ to be better than $\beta(\mathrm{p})$. At the point $\mathrm{p}=\mathrm{f}$ the worker is just indifferent between accepting the contract $\beta$ (f) or waiting until $\mathrm{p}=\mathrm{c}$ and receiving $\zeta(\mathrm{p})$. The worker's optimal strategy is, therefore, to accept the contract $\beta(p)$ if the price is less than $d$, thus $\kappa(p)=\beta(p)$ and $\varphi(p)=\alpha(p)$ if $p<d$. However, for prices that are higher than $d$ the contract agreed between worker and manager is influenced by the worker's ability to delay agreement until $\mathrm{p}=\mathrm{c}$ when the manager exercises its outside option. Thus $\kappa(\mathrm{p})$ is tangential to $\beta(\mathrm{p})$ at $\mathrm{d}$ and increases to $\zeta(\mathrm{c})$ also $\varphi(p)=\xi(p)$ and $\kappa(p)=\zeta(p)$ for $p>c$. The tangency arises because the worker has the option of 
accepting $\beta(\mathrm{p})$ or of waiting until $\mathrm{p}=\mathrm{c}$, optimisation by the worker then implies that $\kappa(\mathrm{p})$ is tangent to $\beta(p)$ at the point $d$.

Case Two : $\gamma=\delta$ and $\lambda<2$

From the calculations contained in Proposition 5 it is clear that for these parameter values the graph on the left of Figure 2 is still a correct representation of the manager's preferences, but the workers preferences now have $\zeta(\mathrm{p})>\beta(\mathrm{p})$ for all $\mathrm{p}$. The region with low prices where players write contracts influenced by $\alpha(p), \beta(p)$ in Case 1 vanishes. Instead the solution has $\varphi(p)+\alpha(p)$ and $\kappa(p)+\beta(p)$.

\section{Conclusion}

It is not obvious that innovation, $R \& D$ and investment are harmed by the absence of binding wage contracts. There are circumstances where contracts can reduce or delay investment. These circumstance arise when labour is relatively patient.

\section{APPENDIX}

Proof of (3) and (4):

If the firm were to start production at time $\Delta \mathrm{t}$ given prices $\mathrm{p}_{\Delta \mathrm{t}}$ and wages $\mathrm{w}$ then the manager's discounted expected profit is

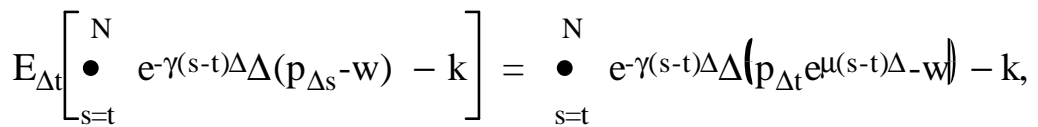

$$
\begin{aligned}
& =\frac{\Delta\left(1-\mathrm{e}^{(\mu-\gamma)(\mathrm{T}+\Delta)}\right)}{1-\mathrm{e}^{(\mu-\gamma) \Delta}} \mathrm{p}_{\Delta \mathrm{t}}-\frac{\Delta\left(1-\mathrm{e}^{-\gamma(\mathrm{T}+\Delta)}\right)}{1-\mathrm{e}^{-\gamma \Delta}} \mathrm{w}-\mathrm{k}, \\
& \rightarrow \frac{1}{(\gamma-\mu)^{*}} \mathrm{p}_{\Delta \mathrm{t}}-\frac{1}{\gamma^{*}} \mathrm{w}-\mathrm{k}, \quad \text { as } \Delta \rightarrow 0 .
\end{aligned}
$$

The first equality follows from the definition of $\mathrm{u}, \mathrm{d}$ and $\pi$. The second sums the geometric progression. 


\section{Proof of Proposition 1:}

First assume the game has an equilibrium $\left(\alpha^{\Delta}(\mathrm{p}), \beta^{\Delta}(\mathrm{p})\right)$ where the players agree in every state $\mathrm{p}$; in this case (5) and (6) become

$$
\begin{array}{ll}
\alpha^{\Delta}(\mathrm{p})= & \mathrm{p} /(\gamma-\mu)^{*}-\mathrm{k}-\left(\delta^{*} / \gamma^{*}\right) \mathrm{e}^{-\delta \Delta} \Pi_{\mathrm{p}} \beta^{\Delta}, \\
\beta^{\Delta}(\mathrm{p})= & \mathrm{p} \gamma^{*} /\left[\delta^{*}(\gamma-\mu)^{*}\right]-\left(\gamma^{*} / \delta^{*}\right) \mathrm{k}-\left(\gamma^{*} / \delta^{*}\right) \mathrm{e}-\gamma \Delta \Pi_{\mathrm{p}} \alpha^{\Delta}
\end{array}
$$

One solution to (A.1) and (A.2) is

$$
\begin{aligned}
& \alpha^{\Delta}(\mathrm{p})=\frac{1}{(\gamma-\mu)^{*}}\left(\frac{1-\mathrm{e}^{(\mu-\delta) \Delta}}{1-\mathrm{e}^{(2 \mu-\delta-\gamma) \Delta}}\right) \mathrm{p}-\left(\frac{1-\mathrm{e}^{-\delta \Delta}}{1-\mathrm{e}^{-(\delta+\gamma) \Delta}}\right) \mathrm{k} \\
& \beta^{\Delta}(\mathrm{p})=\frac{\gamma^{*}}{\delta^{*}(\gamma-\mu)^{*}}\left(\frac{1}{1-\mathrm{e}^{(2 \mu-\delta-\gamma) \Delta}}\right) \mathrm{p}-\left(\frac{1-\mathrm{e}^{-\gamma \Delta}}{1-\mathrm{e}^{-(\delta+\gamma) \Delta}}\right) \frac{\gamma^{*} \mathrm{k}}{\delta^{*}} .
\end{aligned}
$$

There are other solutions, but this is the unique C2 solution with the property that neither player receives a payoff of -8 at zero and neither player receives a payoff of -8 as p tends to infinity. ${ }^{11}$ I rule these out, because neither bargainer would accept a payoff less than zero, that is, what it gets from perpetual disagreement. As $\Delta \varnothing 0$ so $\alpha^{\Delta} \varnothing \alpha^{0}$ and $\beta^{\Delta} \varnothing \beta^{0}$ where

$$
\alpha^{0}(\mathrm{p})=\frac{\delta-\mu}{(\gamma-\mu) *(\gamma-\mu+\delta-\mu)} \mathrm{p}-\frac{\delta}{\gamma+\delta} \mathrm{k}, \beta 0(\mathrm{p})=\frac{\gamma^{*}(\gamma-\mu)}{\delta^{*}(\gamma-\mu+\delta-\mu)(\gamma-\mu)^{*}} \mathrm{p}-\frac{\gamma^{*}}{\delta^{*}(\gamma+\delta)} \mathrm{k}
$$

$\alpha^{0}$ and $\beta^{0}$ are the starting point of an iteration. Fix $\beta^{0}$ (given $\Delta$ sufficiently small this is arbitrarily close to (A.4) for finite $p$ ) and assume the worker accepts offers $\beta 0(p)$ in state $p$. I now calculate the manager's optimal response to this. The manager's payoff, if she ensures agreement by offering the worker the payoff $\mathrm{e}^{\delta} \Delta_{\mathrm{p}} \beta^{0}$ in every state $\mathrm{p}$, is arbitrarily close to $\lim _{\Delta \varnothing_{0}}\left\{\mathrm{p} /(\gamma-\mu)^{*}-\mathrm{k}\right.$ $\left.-\left(\delta^{*} / \gamma^{*}\right) \mathrm{e}^{-\delta \Delta} \Pi_{\mathrm{p}} \beta^{\Delta}\right\}=\alpha O(\mathrm{p})$. As $\Delta \varnothing 0$ the price $\mathrm{p}$ is determined by $\mathrm{dp}=\mu \mathrm{pdt}+\sigma \mathrm{pdz}$. Thus her optimal response as $\Delta \varnothing 0$ requires her to find the best time to receive a linear payoff $\alpha^{0}(p)$ when

\footnotetext{
11 A general C2 solution as $\Delta \varnothing 0$ can be found by a substitution for $\beta^{0}$ in (5) and then applying Taylor's Theorem, or known results on the rate of change of stochastic processes, to give a second order differential equation for $\alpha$.
} 
prices follow geometric Brownian motion. I write this as Problem $(\gamma, \alpha 0(p))$; the first element denotes the optimiser's discount factor and the second denotes the optimiser's reward in each state. The solution to this is well known and can be found in Dixit (1989) or Øksendal (1992). It generates the threshold price ' $a$ ' (defined in (8)) such that for $\mathrm{p}<\mathrm{a}$ the manager waits and for $\mathrm{p}=\mathrm{a}$ she stops the process and receives the reward. Her expected payoff in state $\mathrm{p}$ from the optimal response is $\alpha 1(\mathrm{p})$ below

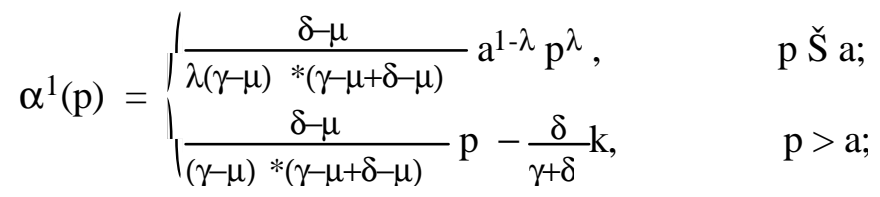

where $\lambda$ is defined in (7).

Now assume that the manager is willing to reach an agreement if she receives $\alpha 0(p)$ in state $p$ and calculate $\beta^{1}(\mathrm{p})$ which is the worker's optimal response to $\alpha^{0}(\mathrm{p})$ as $\Delta \varnothing 0$. As $\Delta \varnothing 0$ the worker's optimal response approaches $\operatorname{Problem}(\delta, \beta 0)$ (in the above notation). Its solution gives a threshold price $\mathrm{b}$ (defined in (8)). For $\mathrm{p}=\mathrm{b}$ the worker prefers to wait whilst for $\mathrm{p}=\mathrm{b}$ he accepts the reward $\beta^{0}$. The worker's payoff from the optimal response in state $p$ is the function $\beta^{1}(p)$

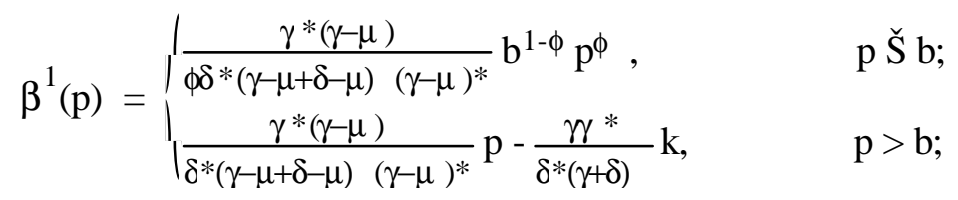

where $\phi$ is defined in (7).

The functions $\left(\alpha^{1}, \beta^{1}\right)$ are shown in Figure 1. By (7) $\gamma=\left(\sigma^{2 / 2}\right) \lambda^{2}+\left[\mu-\left(\sigma^{2 / 2}\right)\right] \lambda$ and $\delta=\left(\sigma^{2 / 2}\right) \phi^{2}+\left[\mu-\left(\sigma^{2 / 2}\right)\right] \phi$, substitution into the definition of a and b gives (A.8). From (A.8) it is clear that $\mathrm{a}>\mathrm{b}$ iff $\gamma<\delta$ and the optimal response to $(\alpha 0, \beta)$ of the more myopic player waits least.

$$
a-b=\frac{k(\gamma-\mu+\delta-\mu)\left(\mu-\sigma^{2} / 2\right)^{2}(\phi-\lambda) \phi \lambda(\gamma-\mu)^{*}}{(\gamma+\delta)(\delta-\mu)(\gamma-\mu)}
$$


Now calculate the manager's optimal response $\left(\alpha^{2}(p)\right)$ if the worker accepts $e^{-} \delta \Pi_{p} \beta^{1}$ in every state $p$ and the worker's optimal response $\left(\beta^{2}(p)\right)$ if the manager accepts e- $\gamma \Delta \Pi_{p} \alpha^{1}$ in every state p. (This gives $(\alpha, \beta)$.)

The manager's optimal response to $\beta^{1}$ is $\operatorname{Problem}\left(\gamma, \mathrm{p} /(\gamma-\mu)^{*}-\mathrm{k}-\left(\delta^{*} / \gamma^{*}\right) \beta^{1}(\mathrm{p})\right)$. This is trivial to solve. First we have $\mathrm{p} /(\gamma-\mu)^{*}-\mathrm{k}-\left(\delta^{*} / \gamma^{*}\right) \beta^{1}(\mathrm{p})=\mathrm{p} /(\gamma-\mu)^{*}-\mathrm{k}-\left(\delta^{*} / \gamma^{*}\right) \beta^{0}(\mathrm{p})=\alpha^{0}(\mathrm{p})$ and if $\mathrm{p}=\mathrm{b}$ then $\beta^{1}(\mathrm{p})=\beta^{0}(\mathrm{p})$. But as $\mathrm{a}>\mathrm{b}$ the function $\alpha^{1}(\mathrm{p})$ is a feasible solution to $\operatorname{Problem}(\gamma, \mathrm{p} /(\gamma-$ $\left.\mu)^{*}-\mathrm{k}-\left(\delta^{*} / \gamma^{*}\right) \beta^{1}(\mathrm{p})\right)$, although this problem has smaller payoffs from agreement, thus $\alpha^{1}(\mathrm{p})$ is an optimal response to $\beta 1(\mathrm{p})$ and $\alpha^{1}=\alpha^{2}$.

Now calculate the worker's optimal response to $\alpha^{1}(\mathrm{p})$ as $\Delta \varnothing 0$ : or Problem $\left(\delta, \mathrm{p} \gamma^{*} /\left[\delta^{*}(\gamma-\mu)^{*}\right]-\left(\gamma^{*} / \delta^{*}\right) \mathrm{k}-\left(\gamma^{*} / \delta^{*}\right) \alpha^{1}(\mathrm{p})\right)$. This is characterised by the threshold price $\pi<$ a (defined by the smallest solution to (9)) such that for $\mathrm{p}<\pi$ the worker prefers to wait and for $\mathrm{p}=\pi$ he prefers to accept the reward and not to wait. This is not a problem with a linear reward (the function $\mathrm{p} \gamma^{*} /\left[\delta^{*}(\gamma-\mu)^{*}\right]-\left(\gamma^{*} / \delta^{*}\right) \mathrm{k}-\left(\gamma^{*} / \delta^{*}\right) \alpha^{1}(\mathrm{p})$ is shown in Figure 1), however, similar techniques can be used to solve this optimal stopping problem. For $p=\pi$ the worker's optimal expected payoff is $\mathrm{Bp}^{\phi}$ and for $\mathrm{p}=\pi$ it is $\mathrm{p} \gamma^{*} /\left[\delta^{*}(\gamma-\mu)^{*}\right]-\left(\gamma^{*} / \delta^{*}\right) \mathrm{k}-\left(\gamma^{*} / \delta^{*}\right) \alpha^{1}(\mathrm{p}):(\mathrm{B}, \pi)$ are determined by the tangency conditions

$$
\mathrm{B} \pi \phi \quad=\pi \gamma^{*}\left[\delta^{*}(\gamma-\mu)^{*}\right]-1-\left(\gamma^{*} / \delta^{*}\right) \mathrm{k}-\frac{(\delta-\mu) \gamma *}{\lambda \delta *(\gamma-\mu) *(\gamma-\mu+\delta-\mu)} \mathrm{a}^{1-\lambda} \pi^{\lambda},
$$

(A.10) $\mathrm{B} \phi \pi^{\phi-1}=\gamma^{*}\left[\delta^{*}(\gamma-\mu)^{*}\right]-1-\frac{(\delta-\mu) \gamma *}{\delta^{*}(\gamma-\mu) *(\gamma-\mu+\delta-\mu)} \mathrm{a}^{1-\lambda} \pi^{\lambda-1}$.

Solving these for $(\mathrm{B}, \pi)$ gives

$$
\beta^{2}(\mathrm{p})= \begin{cases}\mid \frac{\gamma^{*} \pi^{1-\phi}}{\delta^{*} \phi(\gamma-\mu)^{*}}-\frac{(\delta-\mu) \gamma^{*} \mathrm{a}^{1-\lambda} \pi^{\lambda-\phi}}{\phi \delta *(\gamma-\mu) *(\gamma-\mu+\delta-\mu)} & \mathrm{p} \mathrm{\check {S } \pi}, \\ \frac{\mathrm{p} \gamma^{*}}{\delta^{*}(\gamma-\mu)^{*}}-\frac{\gamma^{*}}{\delta^{*}} \mathrm{k}-\frac{(\delta-\mu) \gamma *}{\lambda \delta^{*}(\gamma-\mu) *(\gamma-\mu+\delta-\mu)} \mathrm{a}^{1-\lambda} \mathrm{p}^{\lambda} & \mathrm{a} \cdot \mathrm{p} \pi \\ \frac{\mathrm{p} \gamma^{*}(\gamma-\mu)}{\delta^{*}(\gamma-\mu)^{*}(\gamma-\mu+\delta-\mu)}-\frac{\gamma \gamma^{*}}{\delta^{*}(\gamma+\delta)} \mathrm{k} & \mathrm{p}>\mathrm{a},\end{cases}
$$


and $\pi$ solves (9). (Note: although there are two solutions to (9) it is clear that $\pi=\mathrm{a}$, this is only true for the smaller solution to (9) as the right hand side increases at $\pi=a$.)

It remains to show that $\alpha^{2}(\mathrm{p})$ and $\beta^{2}(\mathrm{p})$ are a stationary equilibrium for the game as $\Delta \varnothing 0$. $\alpha^{1}(p)=\alpha^{2}(p)$ so $\beta^{2}(p)$ is an optimal response to $\alpha^{2}(p)$ as $\Delta \varnothing 0$. By construction $\pi=a$ thus $p>a$ implies $\beta^{2}(p)=\beta^{1}(p)$, hence repetition of the argument above shows that as $\Delta \varnothing 0$ so $\alpha^{2}(p)$ is the optimal response to $\beta^{2}(\mathrm{p})$. Thus at every state $\mathrm{p}$ the functions $\alpha^{2}$ and $\beta^{2}$ describe strategies which are best responses, as $\Delta \varnothing 0$, to each other and so $\alpha^{2}=\alpha$ and $\beta^{2}=\beta$. 


\section{REFERENCES}

BeSTER, H., "Incentive-Compatible Long-Term Contracts and Job Rationing," Journal of Labor Economics , 7 (1989), 238-255.

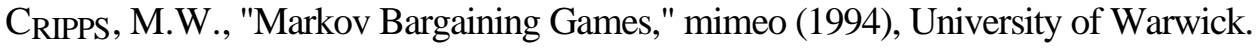

DENNY, K., AND S. NICKELL, "Unions and Investment in British Manufacturing Industry," British Journal of Industrial Relations, 29 (1991), 113-121.

DevereuX, M. B., ANd B. Lockwood "Trade Unions, Non-binding Wage Agreements, and Capital Accumulation," European Economic Review, 35 (1991), 1411-1426.

DIXIT, A., "Entry and Exit Decisions Under Uncertainty," Journal of Political Economy, 97 (1989), 620-638.

DynkIN, E. B., The Theory of Markov Processes (Oxford: Pergamon Press, 1960).

GROUT, P., "Investment and Wages in the Absence of Binding Contracts: a Nash Bargaining Approach," Econometrica, 52 (1984), 449-460.

M ACHIN, S., AND S. W ADHWANI, "The Effects of Unions on Organisational Change and Employment," Economic Journal, 101 (1991a), 835-53.

M ACHIN, S., AND S. W ADHWANI, "The Effects of Unions on Investment and Innovation : Evidence From WIRS," Economic Journal, 101 (1991b), 324-30.

MACLEOD, W. B., AND J. M. MALCOMSON, " Contract Bargaining with Symmetric Information," Canadian Journal of Economics, forthcoming.

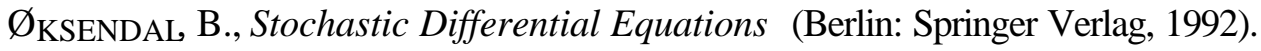

RubinsteIN, A., "Perfect Equilibrium in a Bargaining Model," Econometrica, 50 (1982), 97-109.

ULPH, A., AND D. ULPH, "Bargaining Structures and Delay in Innovation," Scandinavian Journal of Economics, 90 (1988), 475-491.

$\mathrm{V}_{\mathrm{AN}} \mathrm{D}_{\mathrm{ER}} \mathrm{P}_{\mathrm{LOEG}}, \mathrm{R} .$, "Trade Unions, Investment and Unemployment: A Non-Cooperative Approach," European Economic Review, 31 (1987), 1469-1492. 